Volume 9, No.4, July - August 2020

International Journal of Advanced Trends in Computer Science and Engineering

Available Online at http://www.warse.org/IJATCSE/static/pdf/file/ijatcse56942020.pdf

https://doi.org/10.30534/ijatcse/2020/56942020

\title{
Enhance of the Steering Control System for Electric Golf Cart Using MATLAB with FOPID
}

\author{
Mohammed R ABDULLAH ${ }^{1}$, AbdullahiA Ibrahim ${ }^{1}$, Noorulden B Mohamad wasel ${ }^{2}$, \\ Maan M Abdulwahid ${ }^{3}$ \\ ${ }^{1}$ Electrical and Computer Engineering, College of Graduate School, Altınbaş University, Istanbul, Turkey, \\ mrs661990@gmail.com, abdul.ikbu@gmail.com \\ ${ }^{2}$ Department of Computer Techniques Engineering, Al-esraa University College, Baghdad, Iraq, \\ noraldenbasil@gmail.com \\ ${ }^{3}$ Department of Computer Engineering Techniques, Electrical Engineering Technical College, Baghdad, \\ Iraq,engmaan.m@gmail.com
}

\begin{abstract}
Recently several optimization methods have been involves with the enhancement of the control system. One of the most interesting method was based on the use of the Bees Optimization Algorithm (BOA) in controlled system. In this work it has been use it as an enhancement method for controlling the steering control system for electric golf cart, which could increment the progression high stability in voltage and decrease the Steady-state error, high overshoot, inertness for rising time and settling time these issues that we look to unravel it in the controlled system to get limit of dependability that makes controller work in a decent case. The advanced calculations will be utilized from BOA calculation and demonstrate that the utilization with Optimized calculations is superior to the use of the Fractional-order Proportional Integral Derivative (FOPID) controller when making tuning. The applied of the controlled system (Steering Control System for Electric Golf Cart) SCS-EGC system by utilizing MATLAB Simulink.
\end{abstract}

Key words :FOPID, PID, BOA, steering control.

\section{INTRODUCTION}

The Steering Control System for Electric Golf Cart (SCS-EGC) is a system that is designed and demonstrated to be provide the required controlling on the steering for the electric golf cart that employees to make stability on this controlled system to avoid collision whether by trees or another obstacles. Such system has been known to be facing more errors in usage because of controlling usage on the steering and many problems like settling time and rising time it must to calculate them as they prove for the performance by the way the usage of the Bees Optimization Algorithm (BOA) as the extra algorithm that called in MATLAB code to make tuning with Fractional-Order Proportional Integral Derivative
(FOPID) controller by built the transfer function of the controlled System it's called CIFER as one type of steering, its specific for the Electric Golf Cart, after that the transfer function was employing to design a FOPID controller system in order to use the FOPID by adding FOMCOM toolbox its contains five general parameters that called in sequencing F,O,P,I,D. The primary power coordinating system on a vehicle was presented in 1876 by a man with the family name of Fitts, yet little else is pondered him. [1] The accompanying power controlling structure was put on a Columbia truck in 1903 where an alternate electric motor was used to help the driver in turning the front wheels.[1,2]. Robert E. Twyford, an occupant of Pittsburgh, Pennsylvania, fused a mechanical power controlling part as a significant part of his patent U.S. Patent 646,477 gave on April 1900 for the underlying four-wheel-drive system.[3] Francis W. Davis, an expert of the truck division of Pierce-Arrow, began examining how directing could be made less difficult, and in 1926 envisioned and indicated the chief sensible force controlling system[1]. Davis moved to general motors and refined the water driven helped power coordinating structure.

\section{BACKGROUND OF FRACTIONAL ORDER DERIVATIVES AND ITS APPLICATION IN FRACTIONAL ORDER PID CONTROLLER}

The Fractional-Order PID (FOPID) controller, is the extension of the regular PID controller dependent on fragmentary math. For a long time, corresponding fundamental - subordinate (PID) controllers have been well known in ventures for process control applications. Their legitimacy comprises straightforwardness of structure and great execution, for example, low rate overshoot and little settling time which is fundamental for moderate modern procedures. Attributable to the fundamental significance of PID controllers, persistent endeavors are being made to improve their quality and heartiness. In the field of programmed control, the fragmentary request controllers which are the speculation of old-style whole number request controllers would prompt progressively exact and strong 
control exhibitions. Even though it is sensibly true, that the partial request models require the fragmentary request controllers to accomplish the best execution, by and large, the partial request controllers are applied to customary direct or nonlinear elements to improve the framework control exhibitions[4,5].

\section{A MATHEMATICAL MODEL FOR THE STEERING CONTROL SYSTEM FOR ELECTRIC GOLF CART}

The design of the steering control system for Electric Golf Cart can be implemented by using MATLAB Simulink in use the transfer function "Laplace Transform" depends on the standard model of the Steering control system for electric golf cart that taken from the previous researcher as in [1]. So the design of the completed transfer function overall can be written as the equation below:

$$
\frac{453.78}{s^{2}+620.76 s+104.79}
$$

The completed steering control system for electric golf cart as block diagram can be seen in below figure:

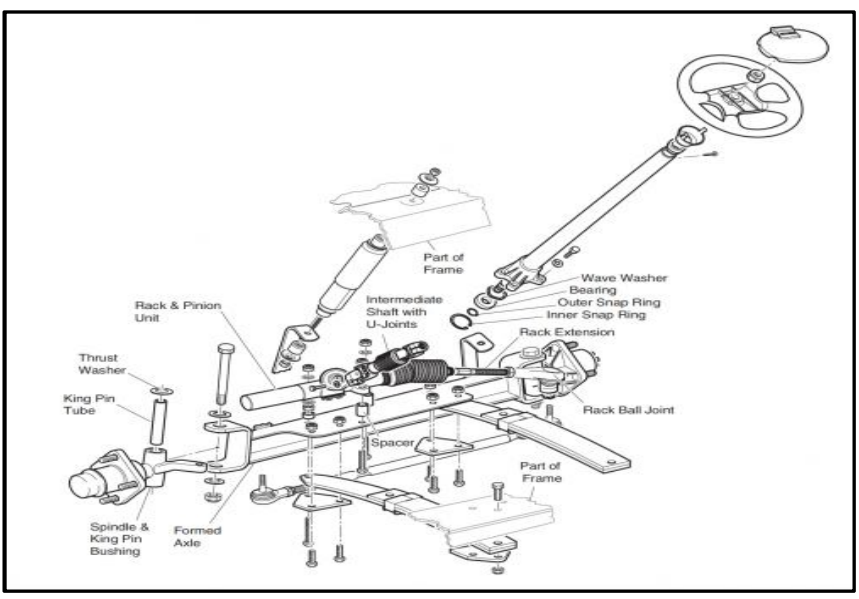

Figure 1:The Complete Steering Control System with General Equipment Concept [14]

\section{METHODOLOGIES}

The design of the proposed system in MATLAB is performed by using Simulink library[6,7] and based on transfer function overall as the equation that mentioned above to make tuning on the proposed system that should use of PID controller is one of the controllers that deals with Proportional (P), Integral (I), Derivative (D) as three scale factors to make tuning on it to prove that usage of PID with the proposed system more efficient than usage without the controller. The design for the proposed system within and without PID controller and FOPID controller can be seen in figures 2, 3 and 4 respectively.

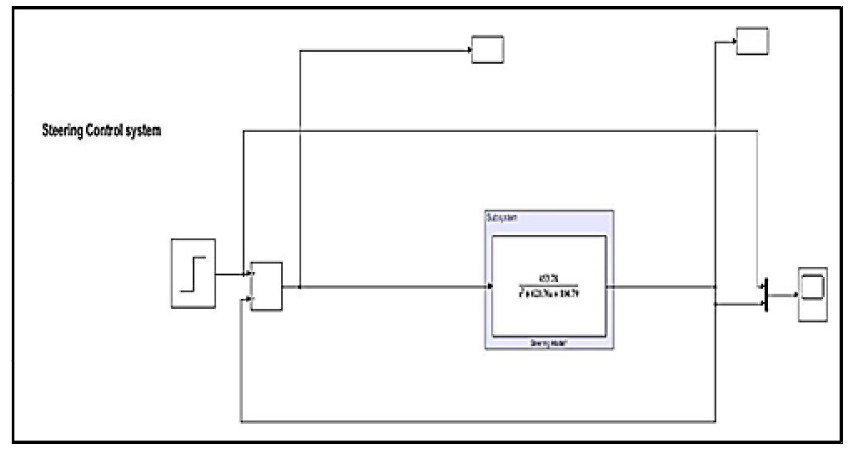

Figure 2: The Completed Steering Control System without Controller

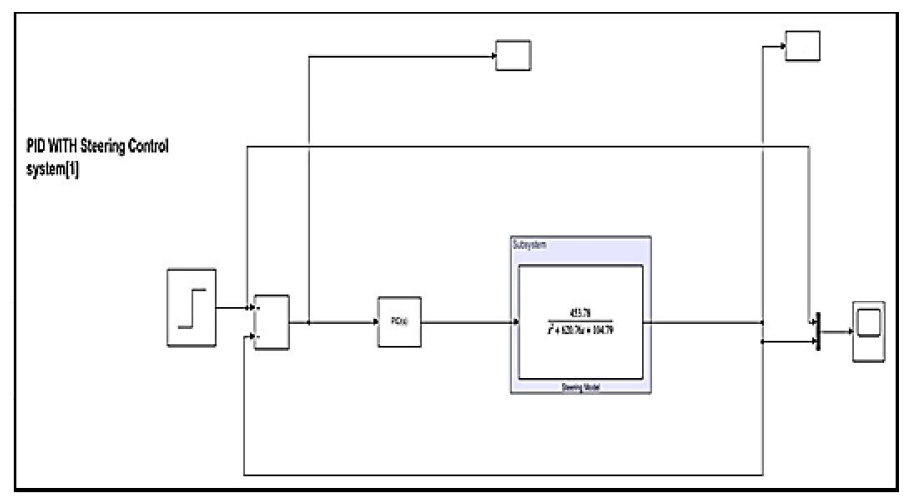

Figure 3: The Completed Steering Control System within PID Controller

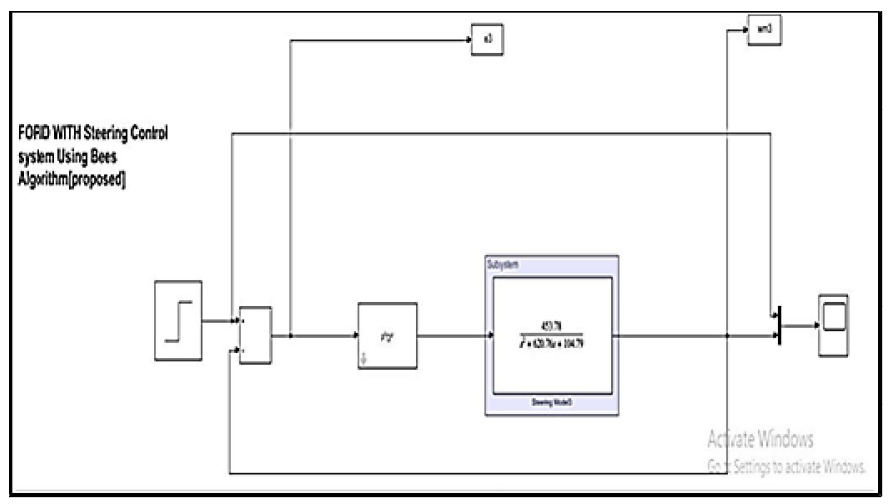

Figure 4: The Completed Steering Control System within Fopid Controller

\subsection{Bees Optimization Algorithm}

A province of bumblebees can expand itself over significant distances and, in various bearings at the same time to collect nectar or dust from numerous food sources[8,9]. A little part of the province continually scans the earth searching for new bloom patches. These scout honey bees move arbitrarily in the zone encompassing the hive, assessing the gainfulness of the food sources encountered. When they come back to the hive, the scouts store the food reaped. Those people that found a profoundly beneficial food source go to a zone in the hive called the move floor, and play out a custom known as the waggle dance[10,11]. Through the waggle move, a scout honeybee conveys the area of its revelation to sit spectators, 
which participate in the abuse of the bloom fix. Since the length of the move is corresponding to the scout's evaluating of the food source, more foragers are selected to reap the best-appraised bloom patches[12,13,14]. In the wake of moving, the scout comes back to the food source is found to gather more food. For whatever length of time that they are assessed as gainful, rich food the scouts will publicize sources when they come back to the hive[15,16,17]. Selected foragers may waggle move also, expanding the enlistment for exceptionally compensating bloom patches, On account of this autocatalytic procedure, the honey bee settlement can rapidly switch the focal point of the rummaging exertion on the most beneficial bloom patches. The Specific Parameters has been sated for the Bees Optimization Algorithm to optimize the Controller. The overall parameters utilized for our work can be seen in table 1 .

Table1: The Overall BOA Parameters for the Steering Control system with FOPID

\begin{tabular}{|c|c|}
\hline $\begin{array}{c}\text { The Parameters for } \\
\text { The bees optimization } \\
\text { algorithm }\end{array}$ & The values \\
\hline $\begin{array}{c}\text { Number of Decision } \\
\text { Variables }\end{array}$ & VarSize $=[1 \mathrm{nVar}]$ \\
\hline $\begin{array}{c}\text { Decision Variables } \\
\text { Matrix Size }\end{array}$ & VarMin=0.1 \\
\hline $\begin{array}{c}\text { Decision Variables } \\
\text { Lower Bound }\end{array}$ & VarMax $=100$ \\
\hline $\begin{array}{c}\text { Decision Variables } \\
\text { Upper Bound }\end{array}$ & MaxIt=1000 \\
\hline $\begin{array}{c}\text { Maximum Number of } \\
\text { Iterations }\end{array}$ & nScoutBee=50 \\
\hline $\begin{array}{c}\text { Number of Scout Bees } \\
\text { Recruited Bees Scale }\end{array}$ & $\mathrm{nBee} 0=$ round $(0.1 * \mathrm{nScoutBee})$ \\
\hline $\begin{array}{c}\text { Neighborhood Radius } \\
\text { Damp Rate }\end{array}$ & rdamp $=0.95$ \\
\hline Neighborhood Radius & $\mathrm{r}=0.01 *($ VarMax-VarMin $)$ \\
\hline
\end{tabular}

Depending on the general equation in the bee's optimization algorithm it should update to be suitable for the controller and also the proposed system to arrive at the best three values for the PID controller, by the way, can utilities the Following general equation it's mentioned below:

$\mathrm{nBee} 0=\operatorname{round}(0.1 * \mathrm{nScoutBee})$

Now by updating on the above equation the best cost will be changing depending on the Maximum of Iteration that will become in the figure below.

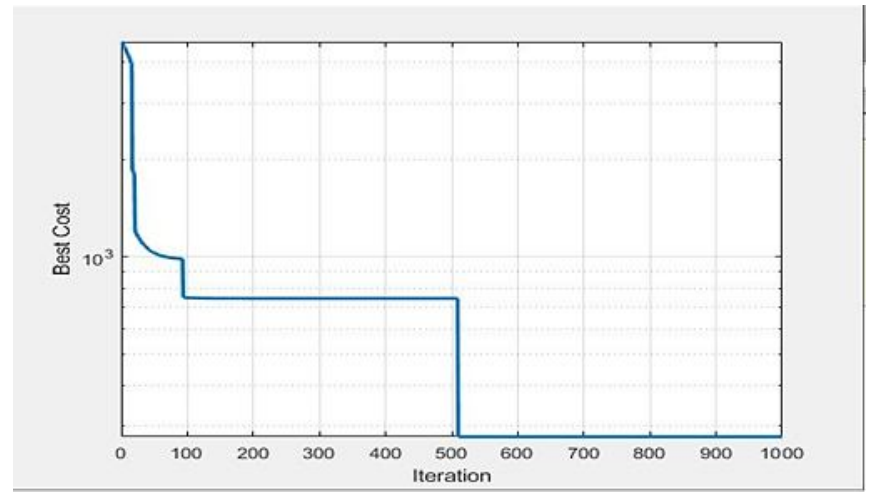

Figure 5: The best cost for bees algorithm within FOPID controller for steering control system

\section{RESULTS AND SIMULATIONS}

The experiments have been tested for the steering control system to test the efficiency of the FOPID on the proposed system $[18,19]$ by comparing with the general parameters to prove the efficiency of the results, the comparison that event between PID-Optimizer [1] and FOPID the proposed solution on the same proposed system:

Table 2: The Overall Convergence quality comparison with Steering Control system

\begin{tabular}{|l|c|c|}
\hline \multicolumn{1}{|c|}{ Parameters } & $\begin{array}{c}\text { Steering-PID } \\
\text { [1] }\end{array}$ & $\begin{array}{c}\text { BOA-FOPID } \\
\text { [Proposed] }\end{array}$ \\
\hline $\begin{array}{l}\text { Minimized-value } \\
\text { of FF }\end{array}$ & $2.235^{*} 10^{\wedge} 2$ & $7.172 * 10^{\wedge} 3$ \\
\hline
\end{tabular}

Table 3:The overall comparison in PID parameters with steering control system

\begin{tabular}{|c|c|c|}
\hline Parameters & $\begin{array}{c}\text { Steering-PID } \\
{[1]}\end{array}$ & $\begin{array}{c}\text { BOA-FOPID } \\
\text { [Proposed] }\end{array}$ \\
\hline$K_{P}$ & 24.92 & 99.865 \\
\hline$K_{I}$ & 0.0098 & 0.9151 \\
\hline$K_{D}$ & 0.2701 & 0.7491 \\
\hline$\lambda$ & - & 0.6999 \\
\hline$\mu$ & - & 0.3394 \\
\hline
\end{tabular}


Table 4: Comparison of transient response with steering control system

\begin{tabular}{|c|c|c|}
\hline Parameters & $\begin{array}{c}\text { Steering-PID } \\
{[\mathbf{1}]}\end{array}$ & $\begin{array}{c}\text { BOA-FOPID } \\
\text { [Proposed] }\end{array}$ \\
\hline$\% M p$ & 0 & 0 \\
\hline$T r$ & 0.125 & 0.029 \\
\hline$T p$ & 0.88 & 0.6 \\
\hline$T s$ & 0.4878 & 0.14 \\
\hline
\end{tabular}

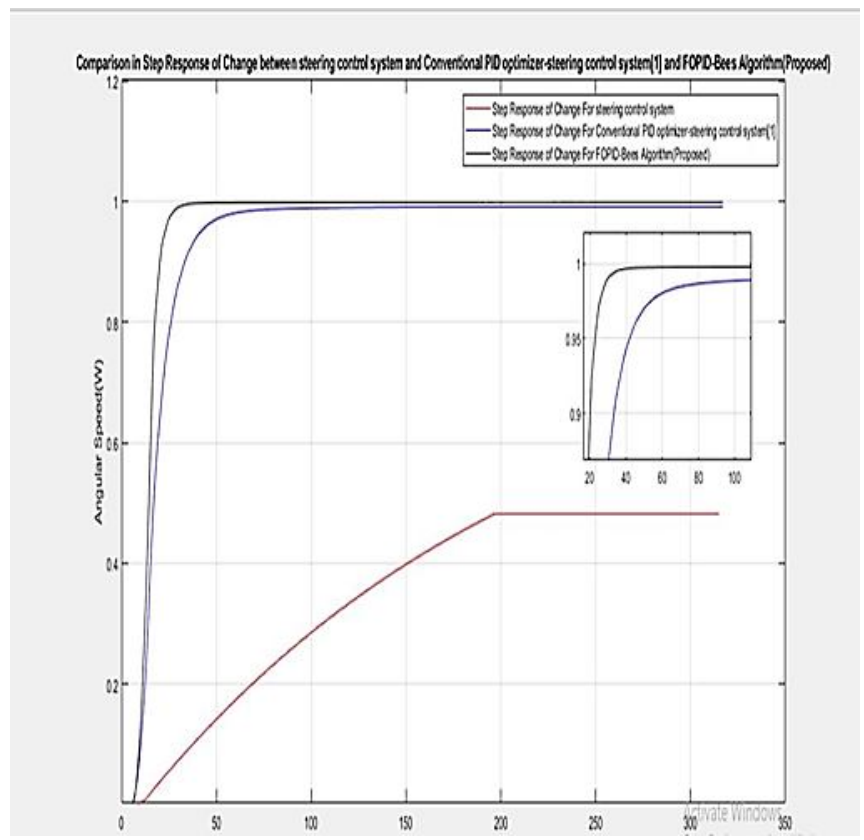

Figure 6: The overall comparison in step response of steering control system for electric golf cart

\section{CONCLUSION}

In this paper, it has been utilized the Bees Optimization Algorithm (BOA) as an optilization based method to be worked with the SCS-EGC system. In addition, the Conventional PID Controller has been utilized and parameter estimations of PID depend on values that have been obtained from the BOA. The results has been tested by using MATLAB program and the experiments has been executed to improve the proposed SCS-EGC System. Results obtained in this work showed an enhancement in the transient response with steering control system, where the parameter values achieved for the raising time, peak time and the settling time were $0.029,0.6,0.14$ second respectively. Such results have showed a significant enhancement as compared to the related results achieved in the same manner by other researchers. For the future work, another optimization method could be performed, tested for getting more reliable results and higher system efficiency in order to enhance the overall system.

\section{REFERENCES}

1. P. Phetnok, A.Lonklang, and S. Tantrairatn, Implementation of Steering-by-Wire Control System for Electric Golf Cart,2019 5th Int. Conf. Control. Autom. Robot. ICCAR 2019, no. October, pp. 373-376, 2019.

https://doi.org/10.1109/ICCAR.2019.8813355

2. N. Lachhab, F. Svaricek, F. Wobbe, H. Rabba, Fractional order PID controller (FOPID)-toolbox, in: 2013 European control conference (ECC), IEEE, 2013, pp. 3694-3699.

3. X. Li, Y. Wang, N. Li, M. Han, Y. Tang, F. Liu, Optimal fractional order PID controller design for automaticvoltage regulator system based on reference model using particle swarm optimization, Int. J. Mach. Learn. Cybern. 8 (5) (2017) 1595- 1605.

4. H. Ramezanian, S. Balochian, A. Zare, Design of optimal fractional-order PID controllers using particle swarm optimization algorithm for automatic voltage regulator (AVR) system, J. Control, Autom. Electrical Syst. 24 (5) (2013) 601-611.

https://doi.org/10.1007/s40313-013-0057-7

5. M. Li, W. Du, F. Nian, An adaptive particle swarm optimization algorithm based on directed weighted complex network, Math. Prob. Eng. 2014 (2014).

6. T.A. Jumani, M.W. Mustafa, M.M. Rasid, N.H. Mirjat, M.H. Baloch, S. Salisu, Optimal power flow controller for gridconnectedmicrogrids using grasshopper optimization algorithm, Electronics, Vol 8, No.1, pp.111,2019

7. Taha, I. A., \&Marhoon, H. M. Implementation of controlled robot for fire detection and extinguish to closed areas based on Arduino. Telkomnika, Vol. 16, No.2,pp. 654-664, 2018.

https://doi.org/10.12928/telkomnika.v16i2.8197

8. H. Gozde, M.C. Taplamacioglu, Comparative performance analysis of artificial bee colony algorithm for automatic voltage regulator (AVR) system, J. Franklin Inst., Vol. 348, No. 8, pp. 1927-1946, 2011.

9. U. Güvenc, A.H. Isik, T. Yi_g i_t, I. Akkaya, Performance analysis of biogeography-based optimization for automatic voltage regulator system, Turkish J. Electric. Eng. Comput. Sci. Vol.24, No.3,pp. 1150-1162. 2016.

10. B. Hekimog $`$ lu, S. Ekinci, Grasshopper optimization algorithm for automatic voltage regulator system, in: 2018 5th International Conference on Electrical and Electronic Engineering (ICEEE), IEEE, pp. 152-156, 2018.

11. B. Sharma, S. Kumar, C. Cattani, D. Baleanu, Nonlinear dynamics of Cattaneo-Christov heat flux model for third-grade power-law fluid, J. Comput. Nonlinear Dyn. Vol.15, No. 1, 2020.

12. S. Ekinci, B. Hekimog lu, Improved kidney-inspired algorithm approach for tuning of PID controller in 
AVR system, IEEE Access, Vol.7, pp. 39935-39947, 2017. https://doi.org/10.1109/ACCESS.2019.2906980

13. I.A. Khan, A.S. Alghamdi, T.A. Jumani, A. Alamgir, A.B. Awan, A. Khidrani, Salp swarm optimization algorithm-based fractional order PID controller for dynamic response and stability enhancement of an automatic voltage regulator system, Electronics, Vol. 8 , No. 12, p. 1472. 2019.

14. Y. R. Mohammed, N. Basil, O. Bayat, and A. Hamid, A New Novel Optimization Techniques Implemented on the AVR Control System using MATLAB-SIMULINK,Int. J. Adv. Sci. Technol., vol. 29, no. 5, pp. 4515-4521, 2020.

15. M. M. Abdulwahid, M. S. Al-Hakeem, M. F. Mosleh, and R. A. Abd-alhmeed, Investigation and optimization method for wireless AP deployment based indoor network $M S \& E$, vol. 745, no. 1, p. 12031, 2020. https://doi.org/10.1088/1757-899X/745/1/012031

16. Shareef $O$ A, Abdulwahid $M$ M, Mosleh M F and Abd-Alhameed R A The optimum location for access point deployment based on RSS for indoor communicationInternational Conference on Modelling and Simulation (UKsim2019), Vol. 20 p 2.1, 2019.

17. M. M. Abdulwahid, O. A. S. Al-Ani, M. F. Mosleh, and R. A. Abd-AlhmeedOptimal access point location algorithm based real measurement for indoor communication in Proceedings of the International Conference on Information and Communication Technology, pp. 49-55, 2019.

18. Mohamed, R. R., Mohamed, M. A., Azmi, K., Rao, E., \&Hashim, W.Indoor smart lighting controlling using human detection. International Journal of Advanced Trends in Computer Science and Engineering, 9(1.1 Special Issue), pp.566-570, 2020. https://doi.org/10.30534/ijatcse/2020/7091.32020

19. Dioses Jr, J. L. AndroiDuino-Fan: A Speech Recognition Fan-Speed Control System utilizing Filipino Voice Commands. International Journal of Advanced Trends in Computer Science and Engineering, Vol. 9, No. 3, 2020. https://doi.org/10.30534/ijatcse/2020/84932020 